\title{
Transdisciplina y percepción en las artes audiovisuales
}

\section{Resumen / Transdisciplina y percepción en las artes audiovisuales}

El texto trata sobre el análisis de la relación entre las disciplinas del dominio de lo sonoro y las disciplinas del campo de lo visual en los lenguajes audiovisuales. Propone instalar el concepto de transdisciplinar para significar la relación estrecha y atravesada entre sonidose imágenes atendiendo en particular al vínculo o lazo que circula entre ellos. Se plantea reflexionar sobre las cualidades perceptivas para la audiovisión, entendida entoncescomo transensorial. Complementando lo perceptivo intenta repensar losestados de la capacidad de audiovisionar estableciendo una analogía con las categorías de la escucha propuestas por Pierre Schaeffer.

\section{Palabras clave}

artes - audiovisión - audiovisual - cine - diseño - Gestalt - imagen - música - percepción - sinestesia - sonido transdisciplina - transensorialidad - video arte.

\section{Summary / Trans-disipline and perception of the audio-visual arts}

The text deals with the analysis of the relationship between disciplines of sounds and the disciplines of vision inside the audio-visual languaje. Suggest the implementation of a trans-disciplined concept to signify the close and crossed relationship between sound and images paying particular attention to the bond or tie which circle among them. States a reflexion over the perceptive qualities for the audio-vision, understand therefore astrans-sensorial. Complementing the perceptual triesto reform the states of the audio-vision capacity establishing an analogy with the characteristics proposed by Pierre Schaeffer.

\section{Key words}

arts- audio-vision - audio-visual - cinema - design - Gestalt - image - music - perception - sound - synesthesiatrans-discipline - trans-sensorial - video art

\section{Resumo / Transdisciplina y percepçao nas artes audiovisuais}

O texto elabora e analiza a relaçao entre as disciplinas atribuídas no campo sonoro e as disciplinas do campo visual naslenguagensaudiovisuais. Propõe instalar o concepto de transdisciplinar para significar a relação estreita e atravessada entre o som e asimagens atendendo principalmente ao vínculo ou laço que circula entre os dois. Se busca refletir sob as qualidades perceptivas para a audiovisão, entendida, desse modo, como transensorial. Complementando a percepcão, intenta repensar os estados da capacidade de audiovisionar establecendo uma analogia com as categorias propostas por Pierre Schaeffer.

\section{Palabras chave}

artes - audiovisão - audiovisual - cinema - desenho - Gestalt - imagem - música - percepcão - sinestesia - som transdisciplina - transensorialidade - video arte.

\footnotetext{
* Centro de Estudios en Diseño y Comunicación, Facultad de Diseño y Comunicación, Universidad de Palermo. infocedyc@palermo.edu Rosa Judith Chalkho: M usical Instituto Universitario Nacional de Artes. Profesora de la Facultad de Diseño y Comunicación de la UP.
} 


\section{La condición transdisciplinar de los objetos audiovisuales}

¿Qué relación o relaciones vinculan a los sonidos con las imágenes en una entidad audiovisual? Esta cuestión es la que orientará los siguientes párrafos en los que intentaré pensar las cualidades de lo visual y lo sonoro en términos de su comportamiento de influencias y confluencias mutuas.

Podríamos denominar esta relación que se da intrínsecamente dentro de una forma audiovisual como interdisciplinaria, donde cada disciplina se conforma como indisoluble de la otra y donde el vínculo que las relaciona viene a constituirse en otra disciplina, cuyo objeto de estudio es del de las funciones y relaciones entre componentes del ente audiovisual. En virtud de esta trama compleja que componen lo visual, lo sonoro y sus relaciones, pareciera que la palabra interdisciplina -en términos de coparticipación de dominios o definida como aportaciones de distintas áreas para la explicación de una situación o problemática- no alcanzara para definir cabalmente la condición de retroalimentación. Es, en términos de atravesamiento mutuo de imágenes y sonidos como se constituye la materia audiovisual, y es por esto que prefiero el término transdisciplinar (de trans $=a$ través de) como atravesamiento disciplinar.

En este punto cabe estipular el significado de algunos conceptos que serán utilizados en este texto:

\section{Ente audiovisual}

Con esta expresión me refiero a la obra o pieza audiovisual como unidad, o sea a la obra en su totalidad. El concepto de "ente" quiere significar la amplia diversidad de soportes sobre los que se corporiza o sostiene lo audiovisual. Este término, entonces, incluye soportes como el video y los distintos géneros artísticos que lo utilizan englobadas en la denominación de video expandido (video arte, video instalación, video escultura, video clip, etc.), las instalaciones visuales y sonoras, las performances, el cine, el cine de animación, los soportes digitales, el net art y otros formatos que continuamente irrumpen conforme el arte se apropia de medios tecnológicos. Si bien las diferencias entre estos soportes son sustanciales, y además, el soporte ya sea físico, ya sea un software, condiciona y determina una estética, la idea de buscar un concepto que los denomine a todos parte de buscar en la relación viso-sonora aquellos aspectos que permitan construir una reflexión teórica del lazo, o bien estudiar el comportamiento del vínculo, importando cualidades y parámetros que se puedan aplicar al estudio en diferentes soportes.

\section{Objeto audiovisual}

La noción de objeto audiovisual es tomada del concepto de objeto sonoro enunciado por Pierre Schaeffer en el Tratado de los Objetos Musicales. El objeto sonoro es aquel sonido que se recorta del contexto por medios técnicos o conceptuales para constituirse en objeto de estudio; se puede decir entonces que un objeto sonoro es un sonido que se constituye en objeto de estudio (Rodríguez, 1998:47,48). Por analogía, el objeto audiovisual es aquel fragmento o recorte de un ente audiovisual que se aísla para su estudio. Cuando en el cine, por ejemplo, se estudia un plano, éste es un objeto audiovisual, aunque el recorte no sólo puede coincidir con la unidad cinematográfica "plano" sino que el objeto puede ser un gesto, un instante, una foto, una secuencia completa o cualquier recorte temporal que imponga la obra o que le interese al observador. Por lo general las líneas de análisis, en lo audiovisual y en el cine en particular, plantean recortes de estudio por disciplina, esto es estudiar la fotografía, luego el montaje y luego los aportes de lo sonoro, etc. Sin dejar de validar este estudio, la idea de objeto audiovisual propone como complemento una mirada integradora, no situada desde la confección de las obras y más tendiente a observar la trama y las acciones de la percepción trazando relaciones entre elementos o "artefactos" y su distribución temporal en los ejes de sucesión y simultaneidad.

Los entes audiovisuales y por tanto sus unidades de estudio de recorte arbitrario, los objetos audio-visuales, sostienen un diálogo en su interior entre sus elementos constitutivos o "artefactos". Introduzco aquí el término "artefacto" como sinónimo de "elemento" , éste último utilizado por ejemplo en diversas teorías del cine para referirse a la fotografía, el sonido, la música, la iluminación, el color, la escenografía, etc. Creo que la palabra artefacto (del lat. arte factus, hecho con arte; obra de arte mecánica) da cuenta en mejor medida del carácter cinético de los elementos; cinético por su condición temporal y por el movimiento hipotético que genera el diálogo o relación con los otros artefactos, "artefacto" alude a funcionamiento y a función.

Ese intercambio invisible, a veces simbólico, otras abstracto entre elementos del dominio de lo visual y elementos del dominio de lo sonoro recrea lazos. Los lazos escapan a lo casual y su ontología se revela al posicionar la mirada sobre las relaciones. Esto es, no diseccionando solamente qué sucede con los sonidos o qué sucede con las imágenes sino haciendo foco a lo que sucede entre ellos.

Es entonces que se redefine la transdisciplina en lo audiovisual como una trama compleja de artefactos del dominio de lo visual y de lo sonoro, donde cada artefacto es en tanto a sí mismo y es en tanto a su relación con los otros; y en donde las relaciones o lazos, cobran tanto valor como cada artefacto. En otras palabras, no se trata del sonido más la imagen, sino de sonidos, imágenes, sus relaciones y la alteración de cada elemento como consecuencia de su vinculación con otros.

\section{La percepción como transensorial}

La concepción transdisciplinar de lo audiovisual implica una percepción transensorial y para arribar a este concepto me valdré de postulados de la teoría de la percepción gestáltica, en especial para la percepción del arte, tomando a Rudolf Arnheim como pilar de esta corriente y relacionándolo con las ideas de Pierre Schaeffer sobre las "escuchas" en torno a la percepción sonora y con los conceptos de Michel Chion sobre el sonido y lo audiovisual. 
“Un todo es más que o diferente de, la suma de sus partes" (Arnheim, 1989:45) es el enunciado de uno de los principios de la Gestalt o teoría de la forma. Los psicólogos gestálticos plantearon algo que hoy es aceptado por toda la psicología: la percepción no es una sumatoria de estímulos aislados. Según la Gestalt existe un mundo físico (construido objetivamente por el análisis metódico) y existe una experiencia perceptiva que no siempre le es fiel, y sucede que esta experiencia se da a través de muy complicados procesos internos. Para Köhler, el resultado final de estos procesos es "la cosa" que está ante nosotros construida a través de fuerzas dinámicas que organizan el campo de la percepción. Estas fuerzas son las llamadas conductas "moleculares" y las conductas molares. Las conductas moleculares son las estudiadas por el conductismo, que reduce el estudio de la conducta a las mínimas expresiones de estímulo-respuesta. "La conducta molecular es aquella que se inicia en la excitación de un receptor sensorial periférico donde se genera un impulso transmitido por la fibra nerviosa, llega a centros nerviosos que producen una respuesta que se transmite por los nervios eferentes y termina en una contracción muscular o en una secreción glandular" (Beamonte, 1996:68); estas conductas se combinan formando conductas más complejas. Oponiéndose al conductismo, Koffka establece que el estudio molecular de las conductas, o sea en forma aislada, pierde el sentido de la totalidad del registro perceptivo, a lo que opone el estudio llamado "masivo" o "molar". Los procesos fisiológicos masivos "no son una suma 0 combinación de procesos nerviosos locales independientes, sino procesos nerviosos en extensión, tales que cada proceso local depende de todos los otros procesos locales dentro de la distribución masiva" (Koffka, 1953:80). Frente a estos conceptos podemos establecer una primera analogía entre la naturaleza transdisciplinar de lo audiovisual, donde lo molecular, cada evento o artefacto por separado, se explica en tanto su interrelación con el total audiovisual (molar) y la idea de percepción transensorial se expresa no como unidades atomizadas, sino como comprensión masiva de los procesos nerviosos; procesos en extensión dependientes unos de otros.

Rudolf Arnheim traslada la teoría gestáltica a las particularidades de la percepción de las artes. En principio, si bien no introduce el término "transensorialidad", algunos de sus conceptos son perfectamente aplicables a esta idea. Al respecto expresa "La unidad de los medios es sugerida también cuando, desde un punto de vista biológico, pensamos en las artes como extensiones de los sentidos. La unidad de los sentidos se manifiesta genéticamente en el hecho de que se puede decir que las diversas modalidades -vista, oído, tacto, etc.- han evolucionado por diferenciación gradual a partir de una dotación mucho más integrada." (Arnheim 1989:75) y para fundamentar esto cita a Law rence E. Marks ${ }^{1}$ quien sostiene que en las formas primitivas de vida tendrían un único sentido perceptivo capaz de percibir distintos estímulos intensos; de esta forma la diferenciación de sentidos sería una cualidad de evolu- ción superior. A partir de esto Arnheim fundamenta la cuestión integrada de la percepción, donde la diferenciación se da sólo en el plano de los sentidos como terminales fisiológicas en tanto que la percepción es una actividad unificada que compone en resultantes los estímulos que le llegan de diferentes canales. También completa esta idea la referencia al musicólogo Erich Maria von Hornbostel "Lo que resulta esencial en lo senso-perceptible no es lo que separa a los sentidos entre sí sino lo que los une: lo que los une con el conjunto de nuestra experiencia (incluso con la no sensorial) y con todo el mundo exterior objeto de la experiencia". ${ }^{2}$

\section{La percepción del movimiento}

Lo audiovisual supone una inscripción en el tiempo. Para la obra pictórica el tiempo transcurre, la obra permanece; el paso del tiempo se convierte en una cuestión de conservación. Sus límites son espaciales y su relación con el tiempo es la permanencia. El tiempo de la percepción es el tiempo que el observador se otorga a la expectación.

La obra audiovisual impone un alcance temporal en el que se despliega, condición a priori absoluta de lo sonoro, no existe sonido fuera de una porción de tiempo. Aunque lo visual carezca de movimiento (foto, instalación estática, etc) al constituirse como audiovisual la conjunción de la imagen fija y el sonido recrean el ente audiovisual. Tomando lo anterior como condición de base de lo audiovisual, mayores son aún las posibilidades combinatorias cuando la materia visual también se mueve, cuando las imágenes recorren el cambio y la permanencia del objeto visual deviene materia temporal. Los objetos audiovisuales son el tiempo que ocupan, la porción de tiempo en que se inscriben.

Aquí entonces vale pensar lo audiovisual como materia sonoro-visual moldeada en tiempo, manifestado como movimiento a la percepción. Este movimiento es descrito por los gestaltistas como la sensación de continuidad producida por la fusión perceptiva de cada uno de los estados o momentos de los objetos y es estudiado principalmente sobre el movimiento estroboscópico, donde la sucesión de imágenes fijas con similitudes próximas a determinada velocidad producen la fusión en un resultado perceptivo de movimiento.

Koffka va más allá y plantea que también el movimiento se percibe desde una sensorialidad múltiple y no sólo a través de la visión "Si el espacio visual, táctil y acústico fuesen tres espacios diferentes, relacionados entre sí sólo por la experiencia, esa experiencia no podía llevar impresión alguna de movimiento, puesto que, conforme con nuestra teoría, esta impresión implica que el proceso psicofísico recorre un mismo espacio. Por consiguiente, si el movimiento estroboscópico puede ser producido por impresiones de diferentes modalidades de los sentidos, debemos concluir, conforme con nuestra teoría que el espacio perceptual es uno y que puede llenarse con objetos relativos a las diferentes modalidades de los sentidos. La experiencia ha decidido evidentemente en favor de la segunda alternativa. Galli pudo 
producir el movimiento estroboscópico combinando dos o tres estímulos que pertenecían a modalidades de la vista, el oído y el tacto. Los sujetos experimentaban una y otra vez el movimiento de un objeto móvil que los "afectaba" de modos diferentes. Estos experimentos arrojan nueva luz sobre la dinámica del movimiento y sobre la estructura del espacio perceptual" (Koffka, 1953:355, 356)

Estos conceptos de Koffka sobre la percepción transensorial del movimiento tienen su aplicación evidente en el cine, donde el movimiento se construye como interacción entre lo sonoro y lo visual; y donde además, esta condición perceptiva viene a jugar roles diversos; se omiten o se refuerzan estímulos desde una paleta inconmensurable de posibilidades y combinaciones. Posibilidades entre las cuales entra la sustitución de una imagen por su sonido creando la ilusión de "haber visto" lo que sólo se escuchó, y luego la inserción de, por ejemplo, éste recurso mencionado como factor de economía narrativa o propiciador de la agilidad del montaje entre otras tantas otras funciones que puede adoptar el recurso, analizables desde la perspectiva de cada obra. Michel Chion analiza esta particular suplantación que se puede dar entre lo visual y lo sonoro llamándola "visuales del oído, auditivos de la vista" para referirse a aquellas situaciones audiovisuales que permanecen impregnadas en la memoria como sensación de otro sentido del que las generó “ ... cierta rapidez otorgada a la imagen parece dirigirse al oído que está en el ojo para convertirse en la memoria en impresiones sonoras. En especial en Ridley Scott, aficionado a combinar, a la inversa de lo que habitualmente suele hacerse, grandes estratos sonoros, amplios y resonantes, en el nivel del sonido, con un hormigueo de la textura visual, en el de la imagen: los primeros podrán muy bien convertirse en recuerdos visuales de espacio, mientras que el segundo dejará la huella de un fenómeno oído." (Chion, 1993:129)

También, a la inversa, lo auditivo modifica la percepción visual, la reverberación y el eco en una banda sonora de cine recrean y impregnan en la memoria la imagen de grandes espacios aunque sólo veamos planos cortos y pequeños ambientes.

Chion explica el ritmo como un elemento clave de la transensorialidad, no es en los sentidos donde la sensación rítmica se percibe, sino que los sentidos ofician como canales y el ritmo se reconstruye y decodifica en algún área cerebral. Si bien el ritmo puede ser expuesto en ritmo de imágenes y ritmo de sonidos, es la organización de eventos en el tiempo - sean estos imágenes, sonidos o una combinación de los dos - lo que determina la sensación rítmica. En este punto Chion amplía esta idea de transensorialidad del ritmo hacia otras percepciones sobre todo en la organización y distribución de artefactos: la textura, el lenguaje y la forma podrían ser algunas (Chion, 1993:130,131).

La Gestalt explica esta "superestructura perceptual" que trasciende a cada sentido con el concepto de "isomorfismo": "El carácter de todo acontecimiento perceptivo reside en su dinámica y es poco menos que independiente del medio concreto en el que se materializa. Esta interpretación se apoya en el concepto de isomorfismo, que fue introducido por la psicología de la Gestalt para describir semejanzas de estructura en medios materialmente dispares. Así una danza y la pieza musical que la acompaña pueden ser experimentadas como si tuvieran una estructura parecida, aún cuando la danza consiste en unas formas visuales en movimiento y la música en una secuencia de sonidos" (Arnheim, 1989:222). De aquí se puede inferir que la palabra "dinámica" como la utiliza Arnheim está fuertemente ligada a la idea de ritmo; esa estructura parecida entre sonido y movimiento se revela así a la percepción por la síncresis, y a su vez esta síncresis se construye en base a coincidencias y puntuaciones rítmicas.

Expuesto esto, solo quedan algunas percepciones exclusivas del dominio de cada sentido; por ejemplo el color para la vista y la sensación de altura para el oído; pero también esta particularidad se ve interferida en la combinación en la síncresis audiovisual, produciéndose objetos audiovisuales de impacto transensorial como consecuencia de unificaciones sincrónicas de elementos dispares. La utilización de colores en sincronía con alturas, aunque estas cualidades sean exclusivas del canal de la visión y de la audición, producen a la percepción la sensación de estar integrados en un sólo objeto audiovisual, tanto ese color como ese sonido provienen de la "misma cosa" y es la coincidencia sincrónica la que mágicamente las une perceptivamente.

“En el modelo transensorial (o meta-sensorial)... no hay dato sensorial delimitado y aislado desde un principio: los sentidos son canales, caminos de paso, más que campos o tierras." (Chion, 1993:131)

Así mismo Chion explica la transensorialidad de esta forma " calificamos de transensoriales a aquellas percepciones que no pertenecen a ningún sentido en particular, pero pueden tomar prestado el canal de un sentido o de otro, sin que su contenido o su efecto queden encerrados en los límites de ese sentido." (Chion, 1999:81)

\section{Eisenstein, Artaud y el teatro oriental: La transdisciplina de los artefactos}

Es interesante complementar lo expuesto anteriormente con lo que teoriza y lleva a la práctica Serguei $M$. Eisenstein con respecto a la integración sonorovisual en el cine, quien, a partir de la irrupción del sonoro plantea la idea del "montaje polifónico". Este montaje que va a hilvanar plano, sonido y música en un contrapunto audiovisual: "Alexander Nevsky es, de alguna manera el ejemplo de todas las combinaciones que se pueden realizar entre la imagen y el sonido. El autor llega aquí a lo que llama "la cuarta dimensión fílmica": una representación audio-visual gracias a la cual tanto el espectador como el protagonista de la novela precitada "escucha la luz y ve el sonido", o mejor, percibe una oculta sincronización interna donde los elementos plásticos y los elementos sonoros encontrarán su completa fusión" (Agel, 1962:46).

Eisenstein retoma filosofías y estéticas de autores y 
extracciones diversas para repensar sobre su objeto de acción, el cine; es por ello que la teoría eisensteniana es múltiple y diversificada. Eisenstein "Conecta un concepto a otro siempre demasiado rápido, ametrallando con sus ideas y quemando las conexiones para devolver al todo su condición de ígneo estallido de fragmentos, propicios para la nueva combinatoria". (Russo, 2003:67). Es así que el impacto de la representación de un espectáculo del teatro japonés Kabuki lo inspira a la consideración de la potencia estética cinematográfica más allá de lo meramente narrativo. En el Kabuki, los sonidos, los espacios, las voces, los movimientos y los gestos no son agregados expresivos a la palabra, sino que constituyen un todo y son tratados como artefactos equivalentes, sin subordinación de algunos elementos a lo verbal. Son procedimientos contrapuntísticos de combinaciones complejas que se significan unos a otros. "Siguiendo su experiencia con el teatro kabuki, Eisenstein confiaba en crear para el cine un sistema en el que todos los elementos fueran iguales y conmensurables: iluminación, composición, actuación, asunto y hasta subtítulos debían estar integrados para que el cine pudiera escapar al crudo realismo que significaba la narración acompañada por elementos accesorios" (Dudley, 1993:76)

Transferencia y sinestesia son las dos herramientas conceptuales que Eisenstein referencia para crear la dialéctica entre artefactos, la transferencia como diálogo entre elementos donde, por ejemplo lo expuesto en palabras, se responde o continúa en un juego de luz y sombra y, la sinestesia, cuando los diversos elementos se combinan al mismo tiempo propiciando la experiencia multisensorial.

Encuentro algunas coincidencias entre ciertos postulados de Eisenstein y los escritos de Artaud sobre el teatro, por ejemplo, la revisión estética a partir de la toma de conocimiento del teatro oriental y de las ideas de comunión de elementos que forman un todo audiovisual y conceptual. Antonin Artaud refiere a propósito de su estudio sobre el teatro balinés: "En el teatro oriental de tendencias metafísicas, opuesto al teatro occidental de tendencias psicológicas, las formas asumen sus sentidos y sus significaciones en todos los planos posibles: producen una vibración que no opera en un sólo plano sino en todos los planos del espíritu a la vez" (Artaud, 1978:84). Estos planos son jugados desde la combinación en igualdad de jerarquías de personajes, gestos, vestuarios, escenografías, sonidos y músicas; no como representación de un texto, sino que la palabra es otro artefacto en esta comunión sutil de elementos.

El teatro oriental se fuga de lo narrativo, desbordando así en "teatralidad pura" y construyendo una compleja gramática de signos situados en cada uno de los artefactos de la escena, donde los significados se encuentran repartidos en cada elemento y los lazos entre ellos se constituyen en materia teatral. En otras palabras es el gesto que comienza con un giro de la mano del actor replica en el sonido del gong y continúa en un gesto del vestuario -esto en el plano de las sucesiones- en tanto que relaciones similares se advierten en el plano de la simultaneidad.
"Asistimos a una alquimia que transforma el estado espiritual en un gesto, el gesto seco, desnudo, lineal que podrían tener todos nuestros actos si apuntaran a lo absoluto" (Artaud 1978:77)

Poéticamente es como Artaud refiere el teatro oriental, siendo que ese estado de espiritualidad se da justamente por la combinación sutil y relevante de los artefactos escénicos, y el todo es dado a una percepción en estado supra; a una percepción del espíritu y de la intelección. Así Artaud promulga un teatro donde el arte y lo bello circulan por la combinación de elementos como potencia expresiva, teatralidad en estado puro opuesta a la narración teatralizada.

\section{Particularidades de la correspondencia entre sentidos: La sinestesia}

El padre Louis-Bertrán Castel en el siglo XVIII fabrica un "clavicordio de colores", donde cada nota corresponde a un color; cada tecla accionaba una cinta de color distinto. Castel expresa que "... en órdenes diferentes las propiedades de los sonidos y los colores son análogas." (en Levi-Strauss 1994:133), y se llama a esta relación entre colores y notas musicales "sinestesia". ¿ Es la sinestesia, esta correspondencia entre notas musicales y colores, una relación taxativa? ¿Existe una percepción que asocie en forma natural tal color a tal nota? o sintetizando: ¿ es el rojo el color de la nota Do? ¿existe tal relación universalmente dada a la percepción, es culturalmente fabricada o pertenece a la naturaleza de la luz y el sonido?

El problema que aquí se plantea puede ser enfocado desde dos ópticas.

La primera es suponer que esta relación de correspondencia entre un sonido y su color es de aplicación universal; suponer que efectivamente existe a priori una combinación dada entre las frecuencias de los sonidos y las frecuencias de los rayos de luz. Planteada ya sea desde la enunciación de leyes de la percepción, en donde esta correspondencia actuaría como condición perceptiva, o ya sea, por procedimientos desde la física, donde la óptica y la acústica realizarían algún cálculo numérico entre valores de frecuencias lumínicas y sonoras para establecer tal relación. Tanto desde la percepción como desde la física el resultado es falaz y además esconde la arbitrariedad de encontrar parámetros pseudo científicos para explicar una producción artística. Qué margen quedaría entonces para la creatividad si la paleta de posibilidades se viera reducida a ejecutar notas con su color predeterminado. La sinestesia entendida en tanto la búsqueda de relaciones prescriptivas entre fenómenos visuales y sonoros ataca quizás el aspecto más sutil, creador y por ende valioso del arte que es el juego combinatorio de elementos; la libertad sobre la creación, en otras palabras, la composición.

El segundo enfoque apunta mirar el clave del padre Castel con su vinculación sonido-luz como una obra en sí misma, donde las relaciones son planteadas no ya con un criterio universalista sino como las relaciones de ése ente audiovisual. El clave "blinda" su paradigma, un universo de leyes para sí mismo y desde aquí establece lo que para esa obra va a ser verdad. Sin ninguna necesidad de explicaciones so- 
bre la verdadera naturaleza de cada nota musical para cada color, este curioso instrumento pasa a pensarse como la idea de alguien que desde su pulsión estética, desde su resonancia creativa articula una correspondencia que es válida; que deviene indiscutible dentro del ámbito de su obra. El instrumento ya no estipula una hipótesis aplicable a otros entes sino que se explica teórica y estéticamente a sí mismo. La sinestesia es válida entonces, entendida como la percepción de correspondencias entre imágenes y sonidos, cuya combinatoria pertenece no a leyes a priori sino a la decisión del realizador y al sistema creado para esa obra.

Una aclaración sobre esta cuestión, si bien es cualidad de los hechos artísticos hacer uso de una total libertad de combinatorias, una mirada histórica sobre el arte muestra la sujeción a las leyes de composición de cada época de acuerdo con los estilos imperantes, vale decir que los conceptos como " posibilidades de combinatorias" y " paradigma" de una obra pertenecen a una concepción contemporánea, aunque es probable que Castel no haya pensado su clave desde este enfoque.

Es interesante mencionar también y con respecto a lo anteriormente analizado las investigaciones de Scriabin y la confección de un teclado luminoso para su obra Prometeo (1908-1910), o en el plano de la literatura a Rimbaud, quien establece una vinculación poética entre las vocales y algunos colores: " $\mathrm{La}$ "I" es recta como el trazo de una boca y evocará el color rojo con la risa de los labios bellos" 3 . Rimbaud blinda una relación entre la letra "I" y el color rojo, y así con las demás vocales. No reclama una ley para la cual estética y perceptivamente o por alguna otra explicación la "I" es roja; la relación es poesía en dos sentidos: es poética la construcción del sistema de vocales-colores y es poética la obra compuesta con este sistema.

Es interesante mencionar otros dos fenómenos vinculados a la sinestesia y a la transensorialidad. En primer término las llamadas "covibraciones" del sonido, término que se refiere a aquellos sonidos que por su frecuencia e intensidad particulares además de estimular el aparato auditivo producen una vibración por simpatía en algunas partes del cuerpo, en especial las frecuencias graves e intensas y el sonido de la propia voz, aquí podemos hablar entonces como lo refiere Michel Chion (1999:81) de "bisensorialidad" donde un mismo estímulo afecta a dos sentidos distintos (oído y tacto).

El segundo fenómeno es el que Arnheim denomina como "resonancia" y se refiere a aquellas percepciones cuyas dinámicas y estructuras producen una sensación casi kinestésica en el cuerpo: "Cuando se mira la imagen ascendente de un arco o una torre en la arquitectura, o la caída de un árbol doblado por la tormenta, se recibe algo más que la información que transmite la imagen. La dinámica que transmite la imagen resuena en el sistema nervioso del receptor. El cuerpo del espectador reproduce las tensiones de balanceo, de la ascensión y de la inclinación de tal forma que él mismo une en su interior las acciones que está viendo realizarse en el exterior."

(Arnheim,1993:47)
Este concepto de resonancia posicionado en la interacción de estímulos y su impacto en las sensaciones corporales podría ser estudiado para dar explicación a conocidos fenómenos que establecen relaciones entre los espacios arquitectónicos y las sensaciones sobre el cuerpo, por ejemplo espacios que impactan en estados de paz sobre los visitantes, de opresión corporal, de pequeñez, etc.

\section{Crítica a la Gestalt}

Así como los postulados de la teoría de la Gestalt anteriormente enunciados actúan como ideas de base para la comprensión y el desarrollo de ideas sobre la percepción múltiple de entidades audiovisuales; otros de sus postulados son cuestionables a la luz de las posteriores corrientes tanto artísticas como psicológicas. La idea de este escrito es tomar aquellos principios gestálticos que permiten construir un ideario de la percepción de entidades audiovisuales y luego escapar de su paraguas para evitar interpretaciones del arte absolutistas o taxativas.

La Gestalt va a delinear una serie de supuestos y condiciones que afectan a la percepción en términos de una mayor o menor inteligibilidad de lo percibido. Por medio de experiencias basadas sobre todo en gráficos y dibujos se estudian factores de contraste, figura-fondo, continuidad de líneas, homogeneidad de texturas entre otros. Estas figuras "tipo" van a producir una comprensión más o menos certera o una distorsión a primera vista de las medidas y formas reales de los objetos de acuerdo a como estén presentadas. Esta "organización del campo" y sus condiciones quedan resumidas en lo que Wertheimer llamó “ley de pregnancia" (Prägnanz), según la cual la organización psíquica sería tan “ buena" como lo permitan las condiciones dominantes. Una "buena organización" es aquella que posee regularidad, simetría y simplicidad; bajo estos aspectos las formas se presentan como más inteligibles a la percepción que aquello irregular, asimétrico y complejo ${ }^{4}$. A primera vista estos conceptos entrarían en contradicción con la esencia del arte y más fuertemente con la concepción de arte a partir del siglo XX, donde justamente los supuestos estéticos que circulan son los opuestos a los valores estéticos clásicos de equilibrio, simetría y regularidad.

¿Cómo se las ingenia Arnheim, entonces para producir una teoría de la psicología del arte o mejor dicho de la percepción del arte desde su pertenencia gestáltica? ¿cómo explicar el arte, y sobre todo a partir del siglo XIX para el que la "buena forma" no sólo no lo define sino que lo contradice?

Arnheim no comete la torpeza facilista de homologar los experimentos perceptivos basados en gráficos y engaños a la vista a la forma de percibir arte, $y$, desde mi punto de vista resuelve esta encrucijada sobre todo cuando introduce y explica los conceptos de "movimiento" y "tensión".

La palabra movimiento además de implicar cambios en el tiempo, se utiliza para denominar ciertas características de la imagen fija, aquella imagen que expresa movimiento aunque no se mueva. La sensación de movimiento en la imagen fija está dada por el 
corrimiento de los elementos del estado de reposo, por el escape del punto de equilibrio, o sea por la tensión que se genera dentro de la propia imagen. Movimiento de las volutas de una columna barroca, movimiento en los pliegues de las vestiduras de una estatua y hasta en la fotografía de un atleta corriendo. La "buena forma", entonces aquí ya se desprende de su valoración de bondad en términos de ser más asequible a la comprensión perceptiva, y la postura gestáltica de Arnheim acepta las complejidades del arte, para nada explicables desde los patterns perceptivos o desde lo naturalmente dado:

"Podría preguntarse cómo se concilia este interés por el movimiento con la afirmación de que todo acto perceptual tiende a la máxima simplicidad. Hacer que una estructura resulte más simple significa reducir su tensión interna. Las direcciones verticales y horizontales son más simples que las oblicuas. Las formas geométricas elementales son más simples que las distorsionadas. Pero los artistas buscan a menudo lo oblicuo y lo distorsionado. Existe, pues en las artes una extendida tendencia a la forma no simple" (Arnheim, 1985:341)

Otro punto cuestionable de la Gestaltheorie es la idea de una diferenciación entre "intuición" e "intelecto", siendo la intuición la actividad vinculada a la percepción integradora y el intelecto la actividad de la capacidad analítica. "El intelecto tiene una necesidad primaria de definir las cosas distinguiéndolas, mientras que la experiencia sensorial directa nos impresiona en primer lugar por la interdependencia de las cosas" (Arnheim, 1989:75). A la luz de nuevas teorías tanto cognitivas como estéticas o sobre la creación advertimos que esta distinción entre intelecto - para referirse a las actividades analíticas- e intuición - para explicar las actividades de la percepción- resulta insatisfactoria. Hay análisis en la capacidad perceptiva como intentaré explicar más adelante- y la capacidad de integración, atribuida a la intuición perceptiva, es actividad de intelección.

Para concluir, la vinculación entre los enunciados de la percepción de la Gestalt y su aplicación a la percepción estética puedo inferir la utilización de los conceptos de la "buena forma" - regularidad, simetría y simplicidad- despejándolos de la valoración de "bondad" y estableciéndolos en líneas de posibles análisis o reflexiones sobre entes u objetos audiovisuales. Estas líneas podrían ser simetría-asimetría, regularidadirregularidad, simplicidad-complejidad, obviedadsutileza, ambigüedad-precisión, tensión-reposo, permanencia-cambio entre otras, aplicables al ente audiovisual en su totalidad o aplicables sólo a algunos de los objetos audiovisuales de ése ente; es decir que cada objeto puede reclamar para sí alguna 0 algunas líneas de análisis que exalten su condición.

\section{Buena forma y diseño}

La construcciones gestálticas en torno al concepto de buena forma, tan cuestionadas para el arte, se manifiestan como más plausibles de aplicación en el campo del diseño. El diseño gráfico va a expresar una dialéctica entre inteligibilidad y estética, o mejor entre comunicación y estética, en tanto que el dise- ño industrial va a producir un diálogo interno entre funcionamiento y estética. Es aquí donde la buena forma se revela, en parte como objeto de estudio de los diseños: el eje comunicacional y funcional se expresa en formas que por lo menos no contradigan la comprensión de la inteligibilidad perceptiva. Un diseño acabado además de belleza expresa su concepto de comunicación y función, siendo esta dialéctica expresada en diferentes resultantes de acuerdo a estilos y movimientos. Cabe señalar otro aspecto del concepto de buena forma, que son sus implicancias culturales en tanto que no son constantes ni universales los parámetros a los que se aplica la regularidad, simplicidad y simetría; de hecho la buena forma, ni aún en diseño, es un absoluto sino que adopta particularidades de estilo y cultura.

La Gestalt se basa en experiencias sobre todo del dominio de lo visual. Rudolf Arnheim desde su psicología de la percepción del arte analiza la cuestión musical produciendo en ocasiones sistemas comparativos con lo visual y en otras tomando los ejes de movimiento y tensión. Otras de sus interpretaciones son a mi entender poco válidas, ya que intentan explicar resultantes expresivas a la percepción por medio del análisis de líneas melódicas y duraciones que derivarían en la sensación de estados como ensoñación, tristeza, languidez, etc.

¿Qué ocurre, entonces con el diseño sonoro? ¿es posible aplicar estos conceptos de comunicación perceptual y buena forma que plantea la Gestalt? Tomaremos para el caso lo que explica Walter M urch, diseñador sonoro de films, en su artículo "Claridad densa - Densidad clara" en ocasión de realizar la sonorización de los pasos de varios robots para el film THX1138 de George Lucas. En principio -relata Murch- comenzó editando cada sonido de paso a cada paso de la imagen; a su vez estos sonidos de pasos los había construido mediante procedimientos de grabación para lograr el timbre que diera referencia de policías-robots metálicos de $300 \mathrm{Kg}$.

"Así que allí estaba yo con mi desbordante canasta de pasos, colocándolos uno a uno, como haciendo un bordado. Todo iba yendo bien, pero muy lentamente. Empecé a temer que no llegaría a tiempo para la mezcla. Afortunadamente, una madrugada, a las 2 de la mañana un hada buena vino a mi rescate en la forma de una repentina y accidental comprensión: que si había un robot en imagen, sus pasos tenían que estar en sincro; si había dos robots, sus pasos tenían que estar en sincro; pero si había tres robots, nada tenía que estar en sincro. 0 dicho de otra manera, cualquier punto de sincro era tan bueno como cualquier otro!" (M urch en www.filmsound.org) ¿Qué sucede aquí con la percepción? justamente la aplicación de teorías de Gestalt, el colectivo "pasos de robots" se escucha perceptivamente como el sonido de esos robots caminando, sin discriminar si cada paso coincide exactamente con su sonido. Aquí la percepción transensorial engloba la imagen con el sonido en un solo objeto audiovisual, se percibe el todo más que sus partes y la totalidad es más significativa que la suma de los artefactos. Así explica Walter M urch esta cualidad perceptiva: "Por algu- 
na razón, pareciera que nuestras mentes pueden seguir los pasos de una persona, y aún los pasos de dos personas, pero con tres o más personas nuestras mentes se rinden, hay demasiados pasos sucediendo demasiado rápidamente. Como resultado de esta rendición, cada paso ya no es más evaluado individualmente. En su lugar, el grupo de pasos es evaluado como una simple entidad, como un acorde de notas." (Murch, en www.filmsound.org.)

Murch cuantifica estos límites en los alcances de la capacidad de discriminación auditiva de la percepción para la sonorización cinematográfica en lo que llama "ley del dos y medio", que en síntesis se explica que para fenómenos auditivo-visuales iguales 0 semejantes, al superar los dos objetos la percepción deja de advertir la exactitud en la sincronización. Es el paso de una relación puntual (punto de sincronización) a una global. Aquí también en el diseño sonoro como en el diseño gráfico e industrial advertimos la dialéctica planteada entre comunicación y estética. Estética en términos de creación tímbrica y organización rítmica de la densidad, y comunicacional en cuanto a la relación del timbre de los pasos con la imagen, metal y peso de los robots y a la composición y organización de los pasos atendiendo a la inteligibilidad de este objeto audiovisual.

\section{Pierre Schaeffer y la percepción del sonido}

En su Tratado de los Objetos Musicales, Pierre Schaeffer reformula, con vigor de teoría revolucionaria, el sonido, la música y su percepción. Construye teoría sin temor a echar mano de fundamentos gestálticos y fenomenológicos y de los aportes de la teoría saussuriana. Una primera aproximación a su pensamiento nos sitúa en la crítica a la propia concepción histórica del sonido; con la palabra sonido se designa un fenómeno físico y con la misma palabra se designa la percepción de este fenómeno. Esto no ocurre para la luz-visión: la óptica estudia el fenómeno físico "luz", mientras que se denomina "imagen" a la percepción de la luz reflejada sobre los objetos. Esta distinción entre el fenómeno físico y el fenómeno perceptual aparece entremezclada en el sonido, entonces; la primera crítica que va a plantear Schaeffer es, a la explicación del sonido desde el enfoque de la acústica; y, al enfoque de la acústica como única explicación de todo el fenómeno sonoro.

\section{Schaeffer y Gestalt}

Schaeffer trasciende el concepto de objeto sonoro de la Gestalt, a partir de la toma de conciencia de la construcción del objeto por parte del sujeto, toma de conciencia que une lo que vemos y oímos a lo que nosotros somos. (Schaeffer 1988:166)

"Para Köhler, Wertheimer o Koffka, la Gestalt representa un nuevo principio de descripción adecuado a la percepción, al comportamiento y a las operaciones intelectuales, opuesta a los conceptos de elemento simple, medida y adición que reinaban en la física" (Schaeffer 1988:166). Aquí advertimos una primera apropiación por parte de Schaeffer de postulados de la Gestalt; se posiciona desde el sujeto, desde el que compone y construye la audición a par- tir de la escucha y, es la escucha (como percepción activa) en su nivel más alto de intelección la que va a catalogar y a definir la paleta sonora. En síntesis, los parámetros tradicionales de la teo ría musical no siempre dan cuenta de las variantes perceptivas, y existen variaciones severas desde lo perceptual que la acústica musical tradicional no alcanza a considerar. Parámetros como altura, duración y timbre (casi considerado éste último como sinónimo de fuente sonora para la teoría musical tradicional) sólo reflejan algunas de las posibilidades de análisis sonoro; en tanto que otras muchas variantes quedan fuera del espectro analizable. Esta cuestión se pone de relieve máxime abarcando la totalidad de lo que establecemos como sonido (la totalidad de lo audible) y no solo tomando en cuenta los sonidos provenientes de los instrumentos musicales tradicionales.

¿Cómo aplica Schaeffer la teoría de la forma? en principio cambia el término forma de la Gestalt por el de estructura, ya que con la palabra forma va a denominar el contorno temporal de los sonidos; luego establece tres grandes niveles de aplicación de la estructura.

En primer lugar la estructura que organiza la combinación de sonidos, que quizás se podría denominar "estructura formal", y que permite advertir, por ejemplo, las relaciones y combinaciones de notas en una melodía. Luego, cada nota de esa melodía se plantea como una estructura en sí misma, pero analizable desde otros criterios y tomando esa nota como una unidad autónoma, podríamos Ilamarla "estructura interna". Esta estructura melódica, al mismo tiempo, se inscribe en un marco o sistema como lo son por ejemplo el sistema tonal, dodecafónico o los modos hindúes. A esta estructura, sobre cuya red se sostiene la melodía del ejemplo Schaeffer la llama "estructura de referencia".

Sobre las estructuras y la percepción Schaeffer instala un interrogante por demás interesante que es situar la opción de trasladar las estructuras perceptivas para la música a estructuras generales de percepción aplicables a otros campos:

“¿estamos ante un problema particular, de la música que incide en nuestras estructuras auditivas, 0 ante un problema general relativo a las propias estructuras de percepción, cualquiera que sea su campo sensible?

En el primer caso, la música, terreno cerrado, sólo le deberá al empirismo de sus propias experiencias el distinguir poco a poco sus objetos, estructuras y sistemas.

En el segundo, la música sería terreno de maniobra de una investigación más general, interdisciplinaria, anunciada muchas veces bajo el vocablo de estructuralismo." (Schaeffer, 1988:169)

Intentaré indagar más adelante en este texto sobre estos conceptos, o sea sobre la viabilidad de exportar modalidades del análisis schaefferiano de la música y el sonido hacia otras áreas artísticas como los discursos y soportes audiovisuales.

Los estados de escucha descriptos por Schaeffer La escucha es un proceso dinámico, condicionado 
por múltiples factores y construido por el sujeto. En este punto se va a situar para reflexionar sobre el sonido desde el lugar de la percepción, mejor dicho de las "percepciones auditivas" como distintos estadíos, categorías y actitudes de escucha. Desde este foco, despojándose de la terminología aplicada a la música por la acústica y por la teoría musical tradicional, establece una taxonomía de lo sonoro, de los "objetos sonoros", desde el saber construido por una súper-escucha, por una percepción activa y conciente; y al mismo tiempo liberada de la pesada tradición. Schaeffer se dispuso a entender el sonido con "oídos de niño", produciendo interrogación sobre cada uno de los supuestos establecidos e intentando despegarse de definiciones más apegadas a lo cultural que al material sonoro.

Schaeffer se basa en la Gestalt, se posiciona en estudiar el sonido dado a la percepción, mejor dicho, el sonido es materia perceptiva; el sonido es como se percibe. La percepción no es para Schaeffer una sola. Plantea estados perceptivos, estados de escucha: oír, escuchar, reconocer, comprender.

\section{Oír}

Es la actitud de escucha no concientizada, la escucha involuntaria. Aquellos sonidos que del entorno que permanentemente arriban al oído y que permanecen sin atención, que no son tenidos en cuenta en forma activa por el receptor. Simplemente recibimos información a través del sistema auditivo. Oír es percibir indicios frente a acontecimientos exteriores. Recibimos, por ejemplo con una actitud pasiva al sonido ambiente en un lugar concurrido cualquiera, hasta que reconocemos allí la voz de alguien allegado y la actitud se convierte en escucha.

\section{Escuchar}

Es la actitud de escucha utilitaria para la vida cotidiana. Comprende atender al sonido y reconocer su procedencia, la fuente sonora que lo originó y hasta identificar el sonido con su fuente sonora como un mismo hecho. Decimos casi indistintamente "suena el teléfono" o "llaman por teléfono", en ésta última el sonido simplemente es su objeto. Este nivel de escucha incluye la escucha semántica, aquella que decodifica significados a partir de la palabra hablada, pero que no presta atención a otras particularidades sonoras. Escuchar no es necesariamente interesarse por el sonido, sino hacer foco en someros aspectos del significado y en la referencia a la fuente sonora. Por ejemplo identificar por el sonido de la voz a una persona conocida (identificación de la fuente sonora) sin preocuparse por las particularidades de las cualidades sonoras en sí mismas fuera del significado y la procedencia. Escuchar es percibir esbozos del objeto para poder identificarlo.

\section{Entender o reconocer}

Entender implica ejercer un recorte o selección sobre la totalidad de la masa sonora dada al oído. Esta selección organiza una relatividad de volúmenes y cercanías de los sonidos circundantes, distinta a los volúmenes y distancias absolutos del entorno sonoro. Por ejemplo, en una reunión de varias personas donde se dan simultáneamente conversaciones, sonido ambiente y música, la audición va ejercer un recorte 0 una preferencia sobre la totalidad de la masa sonora, enfocando prioritariamente a un interlocutor con el que se sigue una conversación o luego orientar la atención auditiva hacia la música cuando suena una canción de nuestra preferencia. Esta selección intencionada de la capacidad de escuchar y de la "mezcla" relativa de intensidades que administra la percepción se pone de relieve si tomamos un registro grabado de la situación ejemplificada en la reunión. La escucha de la grabación se presentará como un bloque homogéneo donde los distintos planos sonoros que creíamos diferenciados aparecen como uniformes; entonces aquí, la percepción ejerce una cualificación compositiva sobre la totalidad sonora.

\section{Comprender}

Comprender es captar el significado del sonido. Significado que abarca la identificación de la fuente sonora, la acción y el contexto del sonido. Comprender vale también para la interpretación de significados del habla y para la decodificación de intenciones y subjetividades del hablante, lo que se denomina la escucha semántica. "Comprender es obtener la información final que buscábamos en el sonido con el acto de escucha. Supone desarrollar una interpretación que se apoya previamente en la escucha y el reconocimiento" (Rodríguez Bravo 1998:202). El sonido es tratado como un signo portador de sentido, sobre esto Schaeffer explica: "Entre las diversas escuchas "significantes" posibles, nosotros nos interesamos naturalmente más en la escucha musical, que se refiere a valores musicales y que da acceso a un sentido musical". Comprender es el estado de escucha mayormente ligado a lo cultural, el sentido atribuido a los sonidos que surge de la escucha comprensiva proviene de asociaciones culturalmente establecidas, no solamente por el habla sino de significaciones entre los objetos y su sonido y dentro del propio discurso musical. Como explica Ángel Rodríguez "Lo que hacemos en niveles de alta especialización auditiva es aplicar patrones de reconocimiento que han sido adquiridos previamente durante largo tiempo de aprendizaje, ya sea mediante un sistema de enseñanza, ya sea mediante la propia experiencia" (Rodríguez Bravo, 1998:204). El oyente especializado comprende cierto lenguaje de sonidos (música, mensajes) y comprende significados revelados por síntomas sonoros.

\section{La escucha reducida: Una actitud de supra-percepción}

Schaeffer sintetiza las actitudes de escucha en un gráfico al que llama "Balance final de las actitudes de escucha" (Schaeffer, 1988:88) y aquí reclasifica oír, escuchar, entender y comprender en dos intenciones: la escucha de los valores (sentido) y la escucha de los indicios (causa). Michel Chion clarifica estos términos como "escucha semántica" (sentido) a aquella orientada a decodificar los significados 
lingüísticos, es la escucha de la comunicación hablada y como escucha causal (causa) a la actitud de remitirse a la fuente que origina el sonido, es la escucha que tiende a identificar la causa o fuente sonora que lo generó.

A partir de establecer esto Schaeffer introduce el concepto de "escucha reducida" o "escucha restringida" para definir aquella actitud que olvida los indicios (causas) y los significados para concentrarse en el sonido en sí, en sus cualidad material desprendido de referentes: "Al rechazar la polarización de la escucha entre acontecimiento y sentido, nos dedicamos cada vez más a percibir lo que constituye la unidad original, es decir, el objeto sonoro."... "Así encontraremos este objeto sonoro, objeto de la actividad que llamaremos aquí escucha restringida" (Schaeffer, 1988:89). (Schaeffer toma el calificativo de reducida o restringida de la noción fenomenológica de reducción de Husserl)

Mediante la escucha reducida es que se accede a definir al objeto sonoro. La escucha reducida aprehende el sonido y lo convierte en objeto de estudio despojándolo de referencialidades e interpretaciones extra-sonoras. Michel Chion comenta al respecto "La escucha reducida es una gestión nueva, fecunda .... poco natural. Altera las costumbres y las perezas establecidas, y abre a quien la aborda un mundo de preguntas que antes ni siquiera imaginaba plantearse." (Chion, 1993:37).

Esta relación objeto sonoro percibido por la escucha reducida, una actitud de escucha minuciosa, interrogativa, actitud que deviene método de estudio; es el puntapié inicial para la taxonomía de los sonidos propuesta por Schaeffer. Una clasificación exhaustiva mediante la cual se pueden caracterizar todos los sonidos y no sólo aquellos denominados "musicales" por la teoría musical tradicional. Los criterios principales de la clasificación son el de forma y materia; y en base a estos aplica cualidades clasificatorias de altura, duración, grano, masa, perfil.

Escapa a este escrito dar cuenta en forma precisa de las minuciosas precisiones, por cierto complejas, de la clasificación schaefferiana, simplemente su mención permite remitir a su teoría y establecer posibles relaciones hacia el campo de lo audiovisual..

\section{Niveles o estados perceptivos de la audiovisión}

El concepto de percepción transensorial del arte, explicado anteriormente, importa aquellos mecanismos y procedimientos de captación de los entes u objetos audiovisuales y donde la distinción entre canales sensitivos como la visión y la audición se ve afectada por fenómenos audiovisuales fuertemente integrados, que producen resonancias también indisolubles en lo perceptual. La percepción, entonces, es la actividad que compone en resultantes los estímulos sensoriales recibidos por canales flexibles. Por otra parte, y con respecto a la escucha, analizamos niveles o categorías de audición y podríamos llamar "análoga" a la escucha causal, aquella que remite a su fuente, y "semántica" a la escucha que requiere el significado, mientras que la escucha reducida es una categoría de audición que va a delibe- rar sobre la cualidad material del sonido mismo. ¿Se podrían cruzar estos conceptos, la transensorialidad de la percepción y la intención de la escucha reducida llevada al terreno de lo audiovisual? Si bien la hipótesis se sabe arriesgada vale considerarla.

\section{La audiovisión semántica}

La escucha semántica es la escucha de los significados de las cosas, de los acontecimientos y de la significación lingüística. Es la escucha que interpreta la palabra. Trasladando esta intención de escucha a la audiovisión podemos ejercer un paralelismo observando al objeto audiovisual como portador de significado. En primer término es audiovisión semántica la audiovisión de textos lingüísticos, las palabras en formato gráfico y sonoro. Pero no es solamente eso, ya que hay significado en cada una de las partículas de los objetos audiovisuales. Gilles Deleuze va a llamar a estos portadores de significación audiovisual "sonsignos" (signos sonoros), "opsignos" (signos ópticos) y "tactisignos" (signos táctiles) entre otros ${ }^{5}$. Una de las líneas de la crítica y de la interpretación estética se basa en esta percepción, en la búsqueda de significaciones estableciendo además que la obra de arte propone múltiples significados; su ontología es polisémica.

A modo de ejemplo, la secuencia audiovisual en la que se ve y se escucha a un personaje abriendo la puerta de una habitación propone un nivel de percepción causal, veo la imagen de una persona abriendo una puerta y escucho el sonido de la misma y, esta situación me remite al modelo de esa acción en el mundo real. En el nivel semántico la escena de la acción de abrir la puerta sería el significante audiovisual que remitiría no a la acción en lo real sino al concepto "abrir la puerta".

Pongamos un ejemplo que clarifique más la audiovisión semántica: Una secuencia fílmica nos muestra a un joven caminando por una calle transitada, escuchamos los sonidos de ese ambiente que en unos segundos disminuyen su intensidad hasta extinguirse, dando paso a una voz masculina que relata una situación cualquiera en primera persona, no vemos al joven mover los labios pero inmediatamente interpretamos que la voz proviene del "pensamiento" de este personaje. Aquí esta situación audiovisual se desarrolla sobre un código que nos va a permitir comprender determinado significado. Cada variante sobre alguno de los artefactos presentes en esta secuencia producirá inferencia sobre el significado, por ejemplo si el joven ahora es un niño, pero la voz sigue siendo adulta y en primera persona e interpretaremos que la imagen es el recuerdo de la niñez del personaje adulto que habla. Sobre este ejemplo, quizás demasiado lineal, podríamos continuar efectuando modificaciones y cada cambio mínimo sobre algún artefacto (iluminación, vestuario, música, etc.) impondrá entonces un cambio en el significado, por ejemplo determinados cambios en la iluminación o en la velocidad (cámara lenta) nos llevarán a suponer que se trata de un sueño o una alucinación etc. La cuestión no termina aquí si además consideramos que estos significados no son unívocos, sino carga- 
dos de ambigüedad, vaguedad y plausibles de múltiples lecturas en ocasiones contradictorias y en otras coexistentes. Además de la significación que cada artefacto provea y que se conjugue en relación a otros, desde el punto de vista del lenguaje audiovisual y relacionado con este nivel de la percepción, podemos hablar de una percepción de las articulaciones del discurso, aquella que advierte la estructura de y entre enunciados audiovisuales. Con respecto a este nivel de audiovisión se puede establecer una distinción entre, los géneros audiovisuales con mayor implicancia de lo narrativo, como el cine, y los géneros que se alejan de la narración como el video arte de concepción abstracta. Es aquí donde estos distintos géneros proponen diferenciaciones con respecto al nivel de la percep-ción semántica

\section{La audiovisión reducida}

La audiovisión reducida surge como concepto de trasladar la idea de escucha reducida enunciada por Schaeffer, esto es, la aprehensión perceptiva del objeto audiovisual desde la transensorialidad y desde una mirada analítica sobre los lazos entre los artefactos que lo componen. Lazos y relaciones que proponen innumerables variantes combinatorias, algunas aplicables desde la taxonomía schaefferiana como la materia, la forma, la masa, la continuidad, la variación y otras que se constituirían como propias del discurso audiovisual abriendo un campo para la deliberación; como el lazo temporal, la clasificación sobre las sincronizaciones, las relaciones espaciales sonido-imagen entre otras. Este estado de la audiovisión es el que sitúa al espectador en la posición de captar los significados (polisémicos) y la materia del arte. La audiovisión reducida no es ingenua, es cuestionadora y movilizadora. Es acto de intelección y expectación estética. Definiendo estas características es interesante posicionar a audiovisión reducida como actividad creadora, como reconstrucción estética, donde el espectador deviene en creador. Esta cuestión se pone en relieve frente a las obras audiovisuales que proponen en su factura la interactividad, entendida no solamente como situaciones de estímulo-respuesta sino como respuestas y acciones esperables y no esperables dentro de una red de posibilidades. Si bien con lo interactivo se advierte la complitud de la obra en términos de la participación del espectador, la mirada que completa la creación persiste en cualquier formato.

Schaeffer expone que la escucha reducida se practica frente a cualquier situación sonora, por ejemplo frente a sonidos cotidianos a quienes este estado perceptivo convierte en objetos sonoros, frente a la audición de paisajes sonoros, ambientes sonoros 0 continums. Sobre esto, entonces, se podría pensar en una audiovisión reducida como captación desde lo estético y lo intelectivo de entornos y ambientes sonoro-visuales realizando como acto de creación una composición audiovisual perceptiva desde el sujeto observador.

\section{Notas}

${ }^{1}$ Marks, Lawrence (1978) E. The Unity of the Senses. Nueva York: Academy Press, En en Arnheim R., Nuevos ensayos sobre psicología del arte.

2 Hornbostel, Erich M.,Von, Die Einheit der Sinne, Melos, Zeitschrift für Musik, (1925), citado en Arnheim R. Nuevos ensayos sobre psicología del arte. Vol. 4- 290-97.

${ }^{3}$ Rimbaud A.. Barcelona: Ediciones 29. En Chion M. (1999). Música, cine, literatura, Barcelona, Editorial Paidós.

${ }^{4}$ El concepto de Prägnanz de Wertheimer está tomado de Beamonte G., Percepción y Gestalt, en. Kauffmann F (comp). (1996) Psicología general. Buenos Aires: Editorial de Belgrano,.

${ }^{5}$ Deleuze, G. (1986) desarrolla estos conceptos en La imagen-tiempo Estudios sobre cine 2, Barcelona: Editorial Paidós, particularmente en el capítulo 2 Recapitulación de las imágenes y los signos.

\section{Bibliografía}

Agel, H. (1962). Estética del cine. Buenos Aires: Eudeba, Colección Cuadernos de Eudeba $\mathrm{N}^{\circ} 84$. Arnheim, R. (1989). Nuevos ensayos sobre Psicología de arte, Madrid, Alianza Editorial, Colección Alianza Forma Arnheim, R. (1985). Arte y Percepción visual, psicología de la visión creadora, Buenos Aires: Eudeba, Colección Temas de Eudeba / Artes visuales.

Arnheim, R. (1993). Consideraciones sobre la educación artística, Barcelona, Paidós Estética.

Artaud, A. (1978). El teatro y su doble, Barcelona: Edhasa.

Beamonte, G. (1996). Percepción y Gestalt, en Psicología general. En Kauffmann F. (comp.). Buenos Aires: Editorial de Belgrano.

Chion, M. (1993) La audiovisión. Introducción a un análisis conjunto de la imagen y el sonido. Barcelona: Editorial Paidós.

Chion, M. (1999). El sonido, música, cine, literatura, Barcelona: Editorial Paidós

Deleuze, G. (1986). La imagen-tiempo. Estudios sobre cine 2. Barcelona: Editorial Paidós.

Dudley, A. (1993). Las principales teorías cinematográficas, Madrid, Ediciones Rialp,

Koffka, K.(1953). Principios de la psicología de la forma, Buenos Aires, Editorial Paidós.

Levi-Strauss, C. (1994) M irar, escuchar, leer. Madrid, Editorial Espasa-Calpe.

Murch, W. Claridad densa - Densidad clara. Extraído el 27 de abril de 2001 desde http://www.filmsound.org Rodríguez Bravo, A. (1998) . La dimensión sonora del lenguaje audiovisual. Barcelona: Editorial Paidós. Russo, E. (2003). La máquina de pensar en Cuadernos del Centro de Estudios en Diseño y Comunicación [Ensayos], Buenos Aires: Facultad de Diseño y Comunicación. Universidad de Palermo. 59-68

Schaeffer, P. (1988) Tratado de los objetos musicales. Madrid: Alianza Editorial, Colección Alianza Música. 